\title{
O itinerário rumo às medicinas alternativas: uma análise em representações sociais de profissionais da saúde
}

\author{
The trajectory towards alternative medicines: \\ an analysis of health professionals' social \\ representations
}

Marcos S. Queiroz ${ }^{1}$

\footnotetext{
1 Centro de Memória da Universidade, Coordenação de Centros e Núcleos Interdisciplinares de Pesquisa, Reitoria, Universidade Estadual de Campinas. C. P. 6023, Campinas, SP 13087-370, Brasil.
}

\begin{abstract}
This article focuses on social representations of alternative medicines by a group of professors from the School of Medicine and health professionals from the public health system in the city of Campinas, São Paulo, basically physicians and nurses. The article also emphasizes personal trajectories by which these health professionals opted for a dissident theoretical and practical perspective vis-à-vis the hegemonic positivist scientific medical paradigm. The research methods were mainly ethnographic, from a phenomenological perspective. The article concludes by sustaining (in theoretical terms) the importance of these dissident perspectives for scientific development.
\end{abstract}

Key words Alternative Medicine; Social Representation; Health Staff

Resumo Este artigo focaliza as representações sociais sobre o conceito de medicina alternativa de intelectuais, professores universitários da Faculdade de Ciências Médicas e profissionais da saúde (médicos e enfermeiros) na rede básica de serviços de saúde de Campinas. O artigo focaliza, também, a trajetória que levou esses profissionais a optar por uma perspectiva teórica e prática dissidente em relação ao paradigma científico positivista hegemônico. Os métodos de investigação utilizados foram principalmente aqueles produzidos pela tradição etnográfica e pela perspectiva fenomenológica. O artigo conclui, sustentando em termos teóricos, com a importância que essas dissidências apresentam para o desenvolvimento da ciência.

Palavras-chave Medicina Alternativa; Representação Social; Profissionais de Saúde 


\section{Introdução}

Este artigo focaliza representações sociais sobre o conceito de medicina alternativa de professores universitários da Faculdade de Ciências Médicas da Universidade Estadual de Campinas (UNICAMP) e da Pontifícia Universidade Católica de Campinas (PUCCAMP) e profissionais da saúde (médicos e enfermeiros) na rede básica de serviços de saúde de Campinas. Além de desvendar o sentido simbólico contido no termo "medicina alternativa", suas influências teóricas, seu sentido epistemológico, seus objetivos e estratégias, o artigo encontra também algumas regularidades na trajetória individual assumida por esses profissionais que, em um determinado momento de suas carreiras, optaram por se comprometer com alguma forma de medicina alternativa, em um contexto fortemente influenciado pela perspectiva positivista tradicional, oposta a essas manifestações.

Para efeitos de operacionalização do estudo, definimos medicina alternativa como uma proposta terapêutica que foge da racionalidade do modelo médico dominante, i.e., da medicina especializada, tecnológica e mercantilizada, enquanto adota uma postura holística e naturalística diante da saúde e da doença. De um modo geral, as medicinas alternativas criticam na medicina alopática o reducionismo biológico, o mecanicismo, a ênfase na estatística, o primado do método sobre o fenômeno e da doença sobre o doente.

Um aspecto teórico fundamental que unifica essas várias medicinas e práticas é a idéia vitalista de que a energia organiza a matéria (e as estruturas orgânicas) e não vice-versa. A ênfase no doente, e não na doença, e a crença de que esta provém, principalmente, de um desequilíbrio interno, ao invés de uma invasão por um agente patogênico externo, são outros pontos comuns.

O caráter não intervencionista, no sentido de se antagonizar com a doença, é um fator importante a ser considerado. Ao invés de intervir no sentido de impedir certas manifestações sintomáticas, essas medicinas e práticas as percebem como sintomas necessários de causas mais profundas, que abrangem o indivíduo e o seu modo de vida em sua totalidade.

Em um plano mais específico, as medicinas alternativas adotadas neste artigo consideram as terapias propostas em 1988 pela Comissão Interministerial de Planejamento e Coordenação do governo brasileiro (CIPLAN), ou seja, homeopatia, acupuntura, técnicas alternativas em saúde mental, termalismo e fitoterapia. Embora haja referência a essas várias práticas, o artigo concentra-se mais diretamente na homeopatia e fitoterapia, além de acrescentar os florais de Bach, uma vez que estes são efetivamente levados em consideração, tanto no ensino universitário como nas práticas terapêuticas da rede básica de serviços de saúde de Campinas.

Os entrevistados foram escolhidos em função de seu papel de liderança intelectual. A tradição etnográfica já demonstrou a utilidade de focalizar agentes em posição de liderança, uma vez que isso permite a expressão do que um conjunto maior da comunidade sente, pensa e faz, mas não se expressa dentro de um quadro de referência formalizado e coerente, deixando esta tarefa para os seus intelectuais (Turner, 1966).

O contexto e o momento da pesquisa, de maio de 1997 a abril de 1998, mostraram-se bastante favoráveis a este trabalho. A reforma administrativa e a municipalização dos serviços de saúde a partir do processo de implementação do Sistema Único de Saúde (SUS), então em curso, implicam, necessariamente, um momento de transição que pressupõe instabilidade em nível institucional. Nesta condição, o universo vivido e representado perde a sua segurança sustentada pela tradição para se colocar como objeto fragmentado, cujas partes se oferecem às várias tentativas de reconstrução, tanto no nível concreto quanto no simbólico. Em uma situação de transição, os valores perdem a sua condição de absolutos, e a realidade passa a ser construída, interpretada, manipulada, destruída e reconstruída, tendo como matéria-prima o confronto de valores múltiplos provenientes da situação vivida individual ou coletivamente pelo ator social. Desse modo, princípios culturais, que normalmente não vêm à tona, tornam-se explícitos e aparentes ao investigador (Turner, 1957).

\section{Alguns pressupostos teóricos fundamentais}

O campo de estudos voltado tanto às racionalidades científicas hegemônicas e oficiais como às racionalidades alternativas está sendo desenvolvido no Brasil sob a liderança dos estudos de Luz (1988, 1996). Trata-se de obras fundamentais ao desenvolvimento dessa área, que desvendam o sentido intrincado entre o relacionamento de uma determinada racionalidade científica e os níveis sócio-culturais e políticos mais amplos. Em outras oportunidades desenvolvemos uma crítica teórica mais consistente (assentada em fatos históricos e etnográ- 
ficos) ao paradigma positivista mecanicista hegemônico na medicina oficial e ao sistema de saúde brasileiro (Queiroz, 1986, 1991, 1998; Queiroz \& Puntel, 1997). No presente estudo, esperamos contribuir com uma pesquisa empírica que tem o objetivo de trazer à tona o sentido do termo "alternativo" em saúde e doença.

O conceito de representação social, empregado intensivamente neste estudo, aparece pela primeira vez como um conceito sociológico em Durkheim (1957), que se opôs às concepções amplamente difundidas, tanto na psicologia (para a qual as qualidades de definir, deduzir, induzir são consideradas como essencialmente inatas ao indivíduo) como para a lógica (para a qual a hierarquia dos conceitos obedece a uma ordem inata às coisas). Durkheim mostra, nesse sentido, que não há nada no nível da percepção (que avalia e compara as coisas externas) que seja independente da dimensão social (nem mesmo categorias elementares como o tempo e o espaço).

Essa postura teórica dimensiona uma realidade social rígida, que deixa pouco ou nenhum espaço para a criatividade no nível individual. O discurso, a semântica e a lógica, no nível das representações sociais, aparecem como reflexos de uma realidade maior. Os indivíduos agem, pensam e se expressam, nesse esquema, como marionetes que incorporam e reproduzem percepções, valores e esquemas classificatórios que lhes são emprestados pela realidade social mais ampla.

O conceito de representação social recebeu um refinamento considerável a partir de Moscovici (1976), em um estudo sobre percepções sobre psicanálise em grupos sociais franceses. Na confluência entre a psicologia e a sociologia, este autor critica a falta de preocupação da psicologia cognitiva com as condições sociais de produção de conhecimento, ao mesmo tempo em que estabelece uma dinâmica entre os níveis individuais e sociais. O seu conceito de representação social adquire, assim, uma dinâmica mais maleável e operacional do que a de Durkheim. Ao invés de mero reflexo de uma estrutura social mais ampla, este conceito traduz um sistema cognitivo que, ao ordenar o real, dá significado ao relacionamento social e permite a comunicação entre membros de uma comunidade.

Outros pesquisadores contemporâneos também contribuíram significativamente na elaboração desse conceito, com problemática principalmente voltada a questões da saúde e doença. Claudine Herzlich (Herzlich, 1973), por exemplo, realizou um trabalho importante sobre percepções de saúde e doença de uma po- pulação de classe média de Paris. Este trabalho analisa a visão de mundo cotidiana e o senso comum sobre os fatores presentes no modo de vida que promovem tanto a saúde como a doença. As representações sociais dos atores entrevistados são reportadas deixando transparecer tanto o sentido como as estratégias de ação.

Boltansky (1979), por sua vez, realizou um importante trabalho sobre classes sociais e a percepção diferencial das funções corporais. Nessa obra, o autor chama a atenção para o aspecto de que a linguagem, o conceito e o nome são indispensáveis para a percepção de um sintoma de doença. $\mathrm{O}$ autor expressa também que, entre as classes sociais mais baixas, a doença tenderia a ser percebida somente enquanto houvesse uma incapacitação de performance social, representada principalmente pelo trabalho, enquanto a noção de saúde envolve necessariamente integração à sociedade através do cumprimento de tarefas entendidas como obrigatórias.

No Brasil, a perspectiva trazida por Moscovici tem influenciado uma importante corrente no interior da psicologia social. Várias teses têm sido produzidas a partir de trabalhos pioneiros na divulgação desta perspectiva, a partir de autores como Spink (1993, 1994), Sá (1993) e Jovchelovitch \& Guareschi (1994).

Schutz (1973), um outro autor importante na delimitação teórica do conceito de representação social, ao integrar as perspectivas legadas por Weber e Husserl, focaliza como a subjetividade, socialmente orientada, se constrói e tipifica a realidade a partir da experiência cotidiana dos indivíduos. Focalizar as regras de tipicidade (baseadas em experiências passadas que, subjetivamente, se abrem em campos de significação e influenciam estratégias e ações intencionais) e o relacionamento entre várias subjetividades (forjando o tecido social), estes são os propósitos principais de sua postura teórica. O estudo da representação social, nesse sentido, necessita de uma abordagem compreensiva, que percebe o ator social como um agente que interpreta o mundo à sua volta com uma atitude que contém intenções e, portanto, um projeto de ação.

A partir dos enfoques de Moscovici (1976) e de Schutz (1973), é possível definir representação social como um tipo de saber, socialmente negociado, contido no senso comum e na dimensão cotidiana, que permite ao indivíduo uma visão de mundo e o orienta nos projetos de ação e nas estratégias que desenvolve em seu meio social. Representações sociais são, portanto, conhecimentos culturalmente carregados, que adquirem sentido e significado ple- 
no no contexto sócio-cultural e situacional em que se manifestam.

É, portanto, um pressuposto fundamental desta pesquisa em que os sujeitos entrevistados têm representações coerentes em relação ao universo vivido e experimentado. Como se trata de profissionais que costumam teorizar sobre a sua prática profissional, ao lado de um conhecimento prático, de senso comum, que forma uma concepção de vida e orienta suas ações individuais, encontramos também conhecimentos teóricos altamente elaborados. Nesse contexto, as representações sociais aparecem como instâncias privilegiadas de investigação científica, uma vez que elas incluem, em menor escala, ingredientes fundamentais do pensamento e da vida social.

Há que se destacar, ainda, o esforço de alguns autores no sentido de conciliar o materialismo histórico com as perspectivas metodológicas de análise sincrônica, principalmente as de pequena escala, desenvolvidas pela antropologia social e cultural. Minayo (1992), por exemplo, ao tentar estabelecer uma conexão teórica entre esses dois níveis de realidade, realizou um esforço genuíno no sentido de abrir o marxismo e estabelecer uma ponte de diálogo com outras tradições teóricas e metodológicas, principalmente aquelas que focalizam o nível do discurso e as representações sociais.

\section{Metodologia de pesquisa}

O método da observação participante, no interior da tradição etnográfica desenvolvida a partir de Malinowsky (1979), e as técnicas de entrevistas semi-estruturadas (Kvale, 1996) foram os principais instrumentos utilizados.

O método qualitativo introduzido pela antropologia moderna coloca o sujeito e o objeto em uma interação que se torna a parte central e inevitável da investigação. Nem o outro é consumido pelo sujeito, nem vice-versa. Nesse espaço, qualquer proposta metodológica fechada estaria fadada ao fracasso. O método deve abrir-se em um processo de negociação perene com a realidade estudada, que significa adotar uma postura maleável, capaz de adaptar o método a cada oportunidade da investigação. Tal postura exige, sem se opor a um levantamento de dados quantitativos, uma avaliação dos imponderáveis da vida social, do colorido emocional presente nos eventos, que escapam ao controle numérico e exige do pesquisador uma abertura emocional e intuitiva.

As entrevistas empreendidas nessa pesquisa focalizam as representações sociais so- bre o conceito de medicina alternativa de oito intelectuais, professores universitários da Faculdade de Ciências Médicas da UNICAMP e PUCCAMP e profissionais da saúde (médicos e enfermeiros) na rede básica de serviços de saúde de Campinas. Estes oito indivíduos foram escolhidos em função de seu papel de liderança intelectual aliada ao comprometimento prático e teórico na promoção de eventos e atividades oficiais que lidam com alguma forma de medicina alternativa. Esses agentes, cinco mulheres e três homens, sete médicos e uma enfermeira, encontram-se na faixa etária de 36 a 54 anos.

As entrevistas com esses indivíduos foram todas gravadas e transcritas. Em média, duraram cerca de duas horas cada uma, e cada ator foi entrevistado duas vezes, sendo a primeira numa perspectiva mais exploratória e a segunda numa perspectiva mais específica, tendo como base pontos levantados da primeira entrevista. Os locais das primeiras entrevistas foram, com apenas uma exceção, os ambientes de trabalho do ator entrevistado. As segundas entrevistas, no entanto, ocorreram ou nas residências dos entrevistados ou na do entrevistador, em um ambiente intencionalmente mais descontraído.

\section{Sentido de medicina alternativa}

De um modo geral, as medicinas e práticas terapêuticas abordadas neste artigo consideram a doença não como resultante de uma intrusão de um agente externo, mas como um conjunto de causas que culminam em desarmonia e desequilíbrio. Curar um paciente, nesse sentido, não significa torná-lo saudável, termo este entendido a partir de um ponto de vista da normalidade funcional. A cura geralmente leva o indivíduo a um nível de saúde superior àquele que usufruía antes do desafio. Isso sugere que períodos de saúde precária são estágios naturais na interação contínua entre o indivíduo e o meio ambiente. Estar em equilíbrio dinâmico significa passar por fases temporárias de doença, nas quais se pode aprender e crescer. O trecho de entrevista abaixo se refere à homeopatia, mas é compatível com as demais práticas consideradas neste artigo:

"A alopatia trata a doença como sendo a causa do problema do indivíduo; já a homeopatia tem a visão do organismo todo em funcionamento. Se o estômago está doente por causa de um problema emocional ou por causa de uma atitude negativa, não é ele que tem que ser tratado, mas o aspecto emocional e mental. É por isso 
que, na homeopatia, é muito importante saber como a pessoa vive, o que ela sente e o que ela faz. Nós entendemos a pessoa num plano global e a doença é apenas um lado desse plano. Combater o sintoma, como o faz a medicina alopática, pode impedir o indivíduo de adquirir um equilíbrio mais amplo e um estágio superior de saúde" (Enfermeira, professora universitária).

Embora as medicinas alternativas sejam consideradas muito mais como redescobertas de práticas antigas do que como abordagens novas, segundo os agentes entrevistados, elas estão fadadas, em um processo dialético, a se tornarem hegemônicas. Isso porque elas obedecem a um princípio organizador mais amplo e mais integrado do que a medicina alopática, o que permite uma resposta mais apropriada com relação aos problemas gerados pela excessiva especialização moderna que impede a apreensão de um sentido de totalidade. O paradigma mecanicista subjacente à medicina alopática moderna, de acordo com a argumentação de praticamente todos os entrevistados, já esgotou suas possibilidades de ampliar a visão humana e, por isso, tende a ser superado por uma perspectiva mais abrangente. Nesse sentido, a revitalização de propostas antigas, como a homeopatia, a acupuntura e outras práticas alternativas, conteria em si a possibilidade de forjar uma nova ciência no interior de um novo paradigma científico, cujo eixo central é a capacidade de integrar e harmonizar a realidade, ao invés de dividi-la e desintegrá-la para efeitos analíticos e de controle operacional.

A teoria de Thomas Khun (Khun, 1975) sobre desenvolvimento da ciência a partir de conceitos como o de paradigma científico, ciência normal e revolução científica é amplamente conhecida pela população pesquisada e considerada um marco de fundamental importância para a edificação de uma ciência que admita seu caráter subjetivo e humano e, com isso, transcenda o positivismo. O ponto chave no pensamento de Khun refere-se ao fato de que o paradigma científico é sustentado basicamente não só por sua consistência lógica e epistemológica, nem exclusivamente, por sua adequação aos fatos, mas, principalmente, pela comunidade científica e pela sociedade mais ampla, em termos que incluem necessariamente interesses sociais, econômicos e culturais.

O movimento alternativo propõe, nesse sentido, uma revolução científica que permitiria à ciência uma maior liberdade dos interesses econômicos e sociais que sustentam a ciência positivista, permitindo, assim, o surgimento de uma ciência mais humana, ecológica e integradora.
O novo paradigma científico a que a população pesquisada se refere denota uma postura que pretende superar o positivismo cartesiano e newtoniano. O termo cartesiano passou a conotar um sentido negativo, incapaz de apreender a complexidade do mundo real. Enquanto Descartes propunha que somente o intelecto teria acesso às idéias claras e distintas e, conseqüentemente, ao pensamento científico, o novo paradigma aponta que a razão é apenas um entre vários atributos humanos que, hiperdimensionado no momento histórico presente, gera desequilíbrio e desintegração. O novo paradigma pretende que outras dimensões, tais como a emoção, a intuição e a sensibilidade, tenham um papel tão importante quanto o intelecto. A harmonização dessas dimensões ampliaria o foco científico dirigido à realidade e traria uma ciência mais harmônica. Como exemplos empíricos e práticos dessa ciência estariam as ciências médicas de origem oriental, a acupuntura, a fitoterapia, massagens orientais, etc. O trecho de entrevista abaixo mostra como uma ciência holística preocupada com a harmonia é possível.

"Eu considero a homeopatia uma ciência e uma arte, que emprega uma observação rigorosa de fenômenos a partir de uma teoria consistente da realidade, com o suporte da sensibilidade e da intuição. A diferença do objeto de estudo da homeopatia e da medicina alopática é a diferença entre estudar algo vivo e algo morto. A ciência cartesiana, que sustenta a medicina alopática, só pode estudar a matéria morta, enquanto a homeopatia exige um paradigma científico muito mais abrangente, capaz de incluir processos energéticos e vitais que pressupõem diferentes qualidades de manifestação de vida. Não há alternativa: a evolução da ciência terá que se libertar da prisão cartesiana e caminhar em direção à vida" (Médico homeopata, professor da UNICAMP).

Este novo paradigma científico é assumido como a base de uma nova visão de mundo cujo principal motivo é, não mais a fragmentação da realidade e a especialização profissional, mas a construção integradora ou holística de uma realidade em sintonia ou em harmonia com um cosmo mais amplo. Essa visão de totalidade encontra expressão metafórica no holograma que é a fotografia do campo de onda luminosa emitida por um determinado objeto. Como, sob certas condições, qualquer peça do holograma reconstitui a imagem completa, ele sugere como equivocada a divisão entre todo e partes (Collier, 1968).

Doença e cura são, nesse sentido, considerados fenômenos complexos que, para serem 
dimensionados, exigem uma perspectiva que inclua aspectos físicos, psicológicos, sociais, culturais, ambientais e espirituais. Perceber esses fenômenos a partir de apenas um desses componentes significa, para a população pesquisada, uma percepção parcial e incompleta. A medicina científica ocidental moderna, ao focalizar apenas o lado biológico, propõe uma prática parcial e reducionista, uma perspectiva estreita que necessita ser ampliada para dar conta dos problemas engendrados pelos fenômenos da saúde e da doença.

O ponto que merece ser destacado nesta postura é o fato de que a superação do paradigma mecanicista não significa a sua exclusão, mas sim a sua transcendência. $O$ trecho de entrevista abaixo confirma esse aspecto.

"Nós precisamos de pessoas capacitadas a realizar um ato médico especializado, mas que tenha por trás a visão integrada do todo. Não somos contra a formação de especialistas, desde que esta pessoa saiba enxergar o indivíduo de uma forma mais ampla, inserida num contexto social, entendendo essa pessoa biologicamente, psiquicamente e, até mesmo, espiritualmente. $O$ médico precisa aprender a superar a dicotomia tradicional entre médico especialista ou generalista, e a perspectiva holística significa exatamente esta superação" (Médica e professora da PUCCAMP).

No novo paradigma holístico, a divisão cartesiana entre corpo e mente é superada por uma perspectiva que integra esses dois elementos em uma dimensão em que a mente assume importância vital. Acredita-se que o estado psicológico do indivíduo é fundamental tanto na eclosão de uma doença como no desenvolvimento da cura. Desse modo, reconhece-se a emoção positiva como um sinal importante para se estabelecer a saúde e, vice-versa, o estado negativo para estimular alguma doença. A cura não é, portanto, entendida como algo proveniente do exterior. Fatores externos podem catalisar o processo, contribuir para tal, mas não podem curar sem a participação de fatores presentes no próprio indivíduo, que precisam ser por ele reconhecidos e promovidos.

Os principais suportes científicos a essa postura, considerados relevantes por todos os entrevistados, referem-se às idéias de Ivan Illich (Illich, 1975), às experiências de Carl e Stephanei Simonton (Simonton et al.,1978) e à obra de Capra (1997). Vamos olhar um pouco mais de perto o sentido do comprometimento com as idéias desses autores.

A obra "A Expropriação da Saúde", de Ivan Illich, publicada em meados dos anos 70, constituiu um marco de extrema importância para esse movimento. Essa obra exprime bem a crítica contra o modo industrial de produção, que, no caso da medicina moderna, centrada no hospital, ocorre em direção contrária à capacidade natural do ser humano de promover o equilíbrio necessário para a produção de sua própria saúde. Um outro aspecto relevante levantado por este autor é a iatrogenia, ou seja, a produção significativa de doenças decorrentes de atos médicos mal conduzidos proporcionados em escala industrial, principalmente pela alta tecnologia hospitalar.

A postura crítica de Illich foi rebatida por Navarro (1976), a partir de um enfoque marxista ortodoxo. O argumento básico era que Illich propunha uma revolta no nível cultural, ou seja, no nível da superestrutura, sem considerar a infra-estrutura econômica e as relações sociais de produção assentadas na exploração de classe. Sem uma proposta que modificasse fundamentalmente esta relação, os argumentos de Illich, ou mesmo as propostas da Organização Mundial da Saúde (OMS), que focalizaremos no tópico seguinte, não passariam de reformas burguesas sem qualquer alcance revolucionário.

Os Departamentos de Medicina Preventiva de Campinas dividiram-se com respeito a esta questão. Enquanto a UNICAMP assumiu o ponto de vista teórico de Navarro, mais comprometida com a extensão da medicina alopática ortodoxa às classes sociais excluídas do que com a mudança do próprio paradigma dominante da medicina, na PUCCAMP, prevaleceu o ponto de vista de Illich, comprometido com uma mudança cultural na cosmovisão da medicina que possibilita, em sintonia com uma gama de racionalidades médicas alternativas, um controle do paciente sobre sua saúde. As partes de entrevistas abaixo exprimem esses vários pontos:

"Em 85, entrei para a pós-graduação em saúde coletiva na UNICAMP, mas cheguei à conclusão de que o seu referencial teórico, o da determinação social da saúde e doença não dava conta do plano individual, pelo qual eu estava mais interessada. Ele questionava a medicina do ponto de vista de sua organização, de sua produção e oferta à população, mas não questionava o paradigma médico e nem admitia alternativas. Nesse tempo, comecei a ler e me interessar sobre homeopatia e outras práticas médicas alternativas, mas esse interesse não batia com a linha de pesquisa que o meu orientador queria pôr em prática. Fui, então, obrigada a interromper meu mestrado, porque não sabia como prosseguir. Não me arrependo, porque isso me permitiu estudar o que eu queria. Na PUCCAMP, 
encontrei a maior força para prosseguir nesse caminho" (Médica homeopata da rede básica).

O estudo dos Simontons (Simonton et al., 1978) sobre formas alternativas de tratamento de câncer nos EUA foi uma outra influência das mais significativas que, para a maioria dos entrevistados, serve como um esteio teórico em favor do movimento alternativo. Segundo esses autores, o estresse emocional tem dois efeitos principais: inibe o sistema imunológico e acarreta desequilíbrios hormonais, que resultam em um aumento de produção de células anormais. Esses dois efeitos criam condições ótimas para o desenvolvimento do câncer. É um fato irrefutável, de acordo com esses oncologistas, que a promoção de estados emocionais positivos leva o organismo a traduzir esses sentimentos em processos biológicos, que começam a restaurar o equilíbrio e a revitalizar o sistema imunológico.

Os Simontons vêem o câncer, portanto, não como um problema meramente físico, mas como um problema da pessoa como um todo. Assim, a terapia por eles adotada não se concentra exclusivamente na doença, mas procura intervir principalmente na atitude subjetiva que o ser humano sustenta diante da vida e de si mesmo. Trata-se, portanto, de uma abordagem terapêutica psicossomática que tem resultado para os pacientes em uma sobrevida duas vezes maior do que a das melhores instituições americanas para o tratamento de câncer e três vezes maior do que a média americana (Simonton et al., 1978). O trecho de entrevista abaixo exprime essa questão.

"O contato com as descobertas dos Simontons foi para mim algo fantástico, porque vinha dar suporte a tudo o que eu estava vivendo. Nessa ocasião, eu estava me submetendo a um tratamento de homeopatia e de massagem Shiatsu. Eu estava percebendo que a doença vinha de dentro de mim e que eu teria que redimensionar toda a minha vida se quisesse conseguir a cura. Foi nesse tempo que encontrei as descobertas dos Simontons. Foi uma experiência muito positiva porque integrou o meu aspecto sensitivo e emocional com o intelectual. Foi a partir daí que me dei conta de que o tratamento que estava experimentando tinha um suporte teórico que poderia revolucionar toda a medicina e, até mesmo, toda a Ciência Ocidental Moderna" (Enfermeira e professora da UNICAMP).

Os profissionais entrevistados mencionam a influência de Capra (1997) como o autor que sistematizou, de um modo consistente, uma dimensão teórica que justifica a construção de um novo paradigma científico. Segundo este autor, a física moderna e, em particular, a Teo- ria dos Quanta, levanta vários problemas e desafia muitos dos princípios sacramentados pela lógica científica moderna. Entre esses problemas, a questão da separação entre o sujeito e o objeto, que é considerado pela ciência positiva clássica como absolutamente necessária para se obter uma visão objetiva da realidade, é posta em questão.

Uma outra implicação significativa dessa teoria é que a natureza não pode ser reduzida a entidades fundamentais, mas tem que ser entendida através da autocoerência, na qual seus elementos constituintes são vistos como uma teia dinâmica de eventos inter-relacionados em que a coerência total de suas inter-relações determina a estrutura da teia.

Com base nesses achados, Capra mostra como a revolução científica na física moderna prenuncia uma revolução iminente em todas as ciências e uma transformação da nossa visão do mundo e dos nossos valores. A partir da nova perspectiva proporcionada pela física moderna, este cientista propõe o surgimento de um novo paradigma baseado em uma concepção sistêmica da realidade. Capra procura mostrar ainda a compatibilidade dos achados da nova ciência com as tradições místicas orientais, como a Ayurveda e o Taoísmo. O trecho de entrevista abaixo mostra a importância desse autor na justificação teórica da perspectiva alternativa:

"A obra de Capra significa para mim uma base teórica fundamental para alguém de formação científica poder voltar-se para essas formas de medicina alternativa sem receio de estar sendo anticientífico ou irracional. O livro tornou-se minha Bíblia" (Enfermeira e professora da UNICAMP).

\section{Outras influências na perspectiva alternativa}

Além das perspectivas teóricas mencionadas acima, um outro ponto extremamente importante a se destacar nas entrevistas diz respeito ao impacto proveniente das idéias difundidas pela OMS a partir dos anos 60. Todos os entrevistados foram, de uma maneira ou de outra, influenciados por essas idéias, que se manifestaram como respostas positivas à frustração diante do ensino universitário ou à prática profissional.

De acordo com a OMS, saúde resulta de um bem-estar físico, mental, social e espiritual, revelando uma perspectiva holística e integradora. Desde 1976, ela preconiza a utilização de práticas terapêuticas alternativas e não institu- 
cionalizadas e estimula a integração de conhecimentos e técnicas de eficácia comprovada existentes na medicina ocidental e nos sistemas de medicina popular tradicional. Na Conferência de Alma-Ata, em 1978 (O’Neal, 1983), a OMS recomendou formalmente a utilização dos recursos da medicina tradicional e popular pelos sistemas nacionais de saúde, reconhecendo, inclusive, os praticantes dessa medicina como importantes aliados na organização e implementação de medidas para aprimorar a saúde da comunidade.

A palavra de ordem da OMS tem estimulado a formação de um sistema de saúde baseado em tecnologia simplificada, porém eficaz, e resgate da responsabilidade da saúde pelo indivíduo. Nessa perspectiva, o terapeuta assume, juntamente com o paciente, o controle do processo de cura, sem rendição ao paradigma científico dominante, à lógica burocrática do sistema de saúde, e à indústria farmacêutica e hospitalar.

Essa postura focalizada em âmbito teórico por O'Neal (1983) mostra também que a ciência médica está inevitavelmente sujeita à ingerência social, e o tratamento médico deve ser realizado a partir de um compromisso com a população, no que diz respeito aos seus símbolos e visões de saúde e doença. Além de reconhecer a importância das dimensões sócioculturais e psicológicas na produção de saúde e doença, a OMS acabou por reconhecer também a importância da dimensão espiritual.

Uma outra característica desse esquema é que o hospital deixa de ser o centro do sistema de saúde e passa a exercer uma função meramente auxiliar. O eixo do sistema passa a ser exercido por uma rede básica, que oferece uma atenção primária de serviços e saúde, gerenciado pelo poder municipal juntamente com representantes da comunidade.

No Brasil, no Relatório Final da 8a Conferência Nacional de Saúde, em 1986 (MS, 1986), aparece pela primeira vez, em documento oficial, a proposta de introdução de práticas alternativas de assistência à saúde, no âmbito dos serviços de saúde, possibilitando ao usuário o direito democrático de escolher a terapêutica preferida. Há também, nesse relatório, a recomendação de inclusão de conhecimento de práticas alternativas no currículo de ensino em saúde. Em 1988, a Comissão Interministerial de Planejamento e Coordenação (CIPLAN), constituída pelos Secretários Gerais dos Ministérios da Saúde, Previdência e Assistência Social, Educação e Trabalho, criou diretrizes, procedimentos e rotinas para a implantação de homeopatia, acupuntura, técnicas alternativas em saúde mental, termalismo e fitoterapia no Sistema Único de Saúde.

Essas medidas são percebidas como altamente positivas pelos entrevistados que, no entanto, reconhecem que a sua implementação tem sido problemática. A introdução de cursos sobre terapias alternativas em faculdades de medicina é raríssima, enquanto a implementação de terapias alternativas na rede básica de serviços de saúde corresponde a uma fração ínfima em relação às formas terapêuticas dominantes da medicina alopática. O trecho de entrevista abaixo revela esses aspectos:

"A primeira vez que entrei em contato com as idéias difundidas pela OMS foi a partir da conexão que tive com o Departamento de Medicina Preventiva e Social. Eu estava muito desiludida com a medicina, mas a partir desse contato, tudo começou a fazer sentido. Compreendi que a medicina especializada focalizava tão mal o problema da saúde e da doença, porque ela era dominada pelo sistema capitalista. Compreendi que a verdadeira medicina teria que se livrar do seu lado mercantilizado, se dirigir à comunidade e adotar uma postura integradora. Foi muito frustrante reconhecer essa verdade $e$ perceber a dificuldade de pô-la em prática numa universidade ou num serviço da rede públi$c a$ " (Médica homeopata da rede pública).

O contexto mais amplo do surgimento de propostas alternativas pode ser traçado a partir do movimento contracultural, tendente ao naturismo e influenciada pelas civilizações do Oriente. Esse movimento desenvolveu uma atitude de oposição à sociedade de consumo, à burocracia e à modernidade, em geral. No âmbito econômico, ao invés de um programa de desenvolvimento assentado na industrialização indiscriminada, preconizou-se o conceito de desenvolvimento sustentado, uma forma mais ecológica de interação com o meio ambiente. Nessa visão de mundo, pressupõe-se uma valorização do corpo, da saúde, da natureza, do prazer e, principalmente, das emoções positivas.

O taoísmo de Lao-Tsé, o zen budismo, a filosofia mística emanada da Índia, em um sentido mais amplo, e a acupuntura, a yoga, as técnicas de massagens orientais e a alimentação macrobiótica, em um sentido mais específico, foram as principais fontes que, no Brasil, influenciaram o movimento alternativo na área da saúde. Mais modernamente, com a abertura do Ocidente à China, houve um renovado interesse pela ciência e arte chinesas. No Brasil, a acupuntura motivou forte interesse, com vários médicos, professores renomados das faculdades de ciência médica indo verificar in lo- 
co ou mesmo aprender a novidade. O segmento de entrevistas abaixo mostra esse ponto:

"Desde estudante, sempre me interessei por outros tipos de medicina. Quando soube que o reitor, juntamente com outros médicos, estavam indo à China para ver como a acupuntura era empregada em hospitais, fiquei ainda mais interessada. Cheguei a fazer um tratamento com acupuntura, que resolveu um problema de alergia que a medicina nunca chegou a curar. Foi a partir daí que me convenci de que a medicina alopática tem a sua eficácia, mas essa eficácia não é e nem pode ser universal. Vários problemas que ela não pode resolver podem ser resolvidos por outros meios e outras tradições científicas ou populares" (Médica, professora da PUCCAMP).

De um certo modo, todos os entrevistados reconhecem-se como politicamente de esquerda, mas de uma esquerda aberta, democrática e não-autoritária. Todos são críticos da sociedade de consumo e favoráveis ao fortalecimento do Estado no que diz respeito à educação e à saúde. No interior de um Estado fortalecido, espera-se a implementação de políticas públicas que estimulem o consumo de medicinas alternativas. Alguns dos entrevistados engajaram-se em movimentos políticos na juventude. Contudo, atualmente, todos deram evidências de estar pouco motivados para um engajamento político maior. $\mathrm{O}$ trecho de entrevista abaixo revela essa questão:

"Sempre coloquei a medicina como suprapartidária. Claro que tenho minhas preferências, eu vou de esquerda, não tem jeito, mas acho que violência não é solução, é repetição. A minha forma política de ação tem sido lutar pela homeopatia no serviço público. O Estado tem obrigação de dar educação, de cuidar da saúde, e nada disso tem sido feito. A gente tem que passar uma consciência para que o povo possa optar pelo tipo de tratamento que ele deseja, e não colocar goela abaixo uma verdade que apenas uma facção defende. Medicina não deveria ser motivada pelo lucro, tem que ser uma obrigação do Estado. Todas as práticas alternativas deveriam ser igualmente incentivadas. Hoje, os sistemas alternativos de cura são quase inacessíveis aos pobres" (Médico homeopata da rede pública).

Entre todos os entrevistados, observou-se uma compatibilidade consistente com o conhecimento popular e o senso comum e uma recusa a admitir uma divisão radical entre conhecimento científico e conhecimento popular, em que o primeiro significa conhecimento verdadeiro e o segundo conhecimento falso. Sendo assim, se um curandeiro for bem-sucedido na utilização de rituais e cerimônias para influenciar a mente e as emoções do paciente, aliviando sua apreensão diante da doença e estimulando poderes curativos naturais que todos possuem, esse curandeiro estaria executando um papel análogo ao do médico alternativo e partilhando com este vários pressupostos, como a unidade de mente e corpo, a influência das emoções e do nível energético sobre a matéria. Dependendo da crença do paciente e da comunidade que o cerca, esse tipo de enfoque pode ser altamente eficaz como já o demonstrara Lèvi-Strauss (1970). Todos os entrevistados consideraram, no entanto, que o grau de conhecimento sistemático e teórico do médico alternativo é maior, mais universal e mais consistente do que o do curandeiro.

Os medicamentos naturais de origem popular são levados bastante a sério. Todos os entrevistados ou receitam ou utilizam ervas medicinais como auxiliares terapêuticos no tratamento de várias doenças. Eles consideram que o princípio ativo purificado é menos eficaz como remédio do que o extrato natural da planta. Trata-se de uma visão oposta à da ciência médica que percebe os elementos residuais como fatores tóxicos ou limitantes do efeito do principal ingrediente ativo de um vegetal.

Entre essas várias influências, é importante mencionar que não foi encontrado qualquer vínculo entre a proposta alternativa e uma proposta religiosa. Todos os entrevistados rebateram com vigor qualquer tipo de associação mais direta com esses campos e a mera sugestão foi considerada inoportuna. Diante da constatação de que muitos curandeiros populares que adotam o espiritismo kardecista ou a umbanda também adotam a homeopatia (Queiroz, 1982), esta foi reconhecida como um vínculo que opera em um nível rudimentar, que (embora mostre compatibilidades com a perspectiva teórica das medicinas alternativas consideradas) não pode contribuir para o desenvolvimento de um novo paradigma científico alternativo. Todos os entrevistados consideram a sua prática influenciada basicamente pela ciência e não pela religião, como mostra o trecho de entrevista abaixo:

"Essas vinculações que, muitas vezes, se faz entre a homeopatia e espiritismo só servem para denegrir a homeopatia. Não se deve misturar conhecimento científico com astrologia, esoterismo e, principalmente, com religião. O homem é um ser social, é um ser que tem suas crenças, um ser político, mas o médico, diante do paciente, não pode ter nenhum tipo de vínculo nessa base. Diante dele, ele não tem religião, nem política, ele é um profissional que deve estar totalmente aberto para o outro sob a influência do método científico" (Médico homeopata, professor da UNICAMP). 


\section{A busca por uma medicina alternativa}

No âmbito psicológico e subjetivo, um padrão comum de comportamento foi observado em todos os profissionais entrevistados, já no tempo da faculdade: uma profunda insatisfação com o programa de ensino e com o modo considerado desumano de se tratar pacientes no hospital. Em todos os casos, constatou-se uma frustração diante da profissão escolhida, que antecedeu à procura por alternativas.

Junto a essa frustração que, em alguns casos, chegava a ponto de propor uma nova profissão, vinha o conflito da exigência de renunciar à conquista de ser estudante ou jovem profissional da prestigiosa profissão médica. O segmento de entrevista abaixo focaliza esse ponto:

"Logo depois de entrar na faculdade, quando estava no terceiro ano, sabia que nunca poderia aceitar tratar doentes como coisas, como acontecia no hospital. Foi o começo de um tempo em que passei a questionar a prática médica e, depois, a própria medicina. No início, eu sofri muito e cheguei a pensar que não tinha vocação para ser médica" (Médica homeopata da rede pública).

O choque da transição da teoria para a prática, do período de estudante para o de responsabilidade profissional é, particularmente, intenso entre médicos recém-formados (Fox, 1975). Quando o jovem profissional começa a pôr em prática o conhecimento adquirido em universidade, percebe logo que o mundo está longe de ser compatível com a racionalidade ideal da ciência. Além disso, a prática médica, baseada em decisões que se tomam a partir da racionalidade do sistema médico-hospitalar, nem sempre está de acordo com o senso moral do profissional. O tempo de consulta é limitado, os medicamentos são quase que impostos pela indústria farmacêutica, a decisão sobre um procedimento terapêutico deve se adaptar às condições e às prioridades existentes. O mercado de trabalho é competitivo e, muitas vezes, exige desses profissionais vários empregos. Tudo isso leva o profissional a situações que o predispõe ao estresse, à insatisfação e ao questionamento.

Além desses fatores, recusar os procedimentos consagrados pela ciência e abraçar um método alternativo significa um perigo de retrocesso em termos de ascensão social, já que implica numa renúncia aos caminhos trilhados pela elite intelectual e uma afirmação de uma proposta que esta elite despreza, ou seja, uma prática considerada pré-científica. Os trechos de entrevista abaixo enfocam esse problema:

"Foi na residência em psiquiatria que experimentei o primeiro momento de crise pessoal em que questionei a orientação da faculdade de medicina. Foi lá que me dei conta da influência do sistema econômico nas nossas decisões clínicas e do fato de que os médicos receitavam muito mais de acordo com a propaganda dos laboratórios do que pelo conhecimento científico. Foi muita insatisfação e frustração. Quando comecei a me interessar por homeopatia, eu hesitei muito, fiquei preocupado com o que meu pai, que também é médico, iria pensar, porque a homeopatia é vista como um método sem base científica" (Médico homeopata da rede pública).

"Em 1991, entrei numa crise pessoal que me obrigou a interromper meu mestrado na UNICAMP. A crise foi tão grande que me levou à doença física. Foi uma ruptura em minha personalidade, porque, quando fui entrando em contato com situações espirituais, comecei a entender uma outra visão de mundo que era antagônica a tudo que eu tinha estudado. Eu tive que jogar muita coisa fora que antes eu considerava preciosa" (Médica, professora da PUCCAMP).

As perspectivas de solução para a crise pessoal vieram com o entendimento de que a medicina então vigente estava subjugada aos interesses do capitalismo e servia, antes dos propósitos ideais da ciência, à exploração do trabalho e, conseqüentemente, à injustiça social. Todos os entrevistados perceberam que o estudo da dimensão social da saúde e da doença poderia trazer de volta a idéia original de ciência comprometida única e exclusivamente com a verdade. Seis dos oito entrevistados chegaram a realizar sua residência ou pós-graduação ou em departamentos de medicina preventiva e social ou em faculdade de saúde pública e aprofundaram esta compreensão através do contato com as ciências sociais aplicadas à saúde e à medicina. $\mathrm{O}$ trecho de entrevista abaixo mostra bem este aspecto:

"Logo depois de formada, não demorou muito tempo para ficar completamente desiludida com a profissão e com meu trabalho. O sofrimento da população, o mau atendimento, a falta de recursos, a injustiça social, o tipo de atenção que não vai às causas da doença, tudo isso foi me abalando e me fazendo buscar alternativas de vida. O tempo passava, e após dez anos nesse tipo de trabalho, eu não agüentava mais. Então, resolvi voltar a estudar, que significava para mim preencher um espaço mais nobre de pensar o problema saúde em termos sociais. Essa decisão significou para mim uma questão de sobrevivência em termos pessoais e espirituais" (Enfermeira e professora da UNICAMP).

Todos os que perceberam uma saída para sua angústia profissional na perspectiva acadêmica voltada para as ciências humanas vi- 
ram-se em um impasse, diante da constatação de que a perspectiva social da saúde e medicina era uma dimensão limitada, como mostra o trecho de entrevista abaixo:

"Depois da crise que sofri a partir do terceiro ano da faculdade, acabei fazendo residência em medicina preventiva. Embora tenha reconhecido que essa decisão foi importante e, sem querer desmerecer a qualidade de uma medicina que tem o social como parâmetro, ao final da residência, cheguei à conclusão que essa experiência foi insuficiente para alimentar os meus anseios por uma medicina mais holísica, mais próxima da experiência emocional e de vida do paciente" (Médica homeopata da rede básica).

A opção por algum tipo de medicina alternativa não significa negar os procedimentos da medicina oficial, mas incluí-la em uma dimensão mais abrangente. Com respeito a doenças infecciosas agudas em organismos fragilizados, por exemplo, nenhum dos entrevistados foi radical a ponto de descartar totalmente o tratamento alopático. Todos os entrevistados chegaram à conclusão de que há casos em que a prática alternativa não dá conta, sendo necessário recorrer a um especialista. O segmento de entrevista abaixo dimensiona esse aspecto:

“Os medicamentos alopáticos são necessários. Seria loucura lutar contra os antibióticos. Não se luta contra a alopatia, mas a favor de algo mais sutil no enfoque de saúde e doença. Embora a alopatia não seja dona da verdade inteira, há momentos em que ela é fundamental. A homeopatia e a alopatia são coisas que se somam; não se subtraem, se complementam" (Médico homeopata da rede básica).

De todas as formas alternativas, a homeopatia foi a que mais facilmente se relacionou com o sistema público de saúde graças a três fatores principais: o peso de sua tradição no Brasil (Luz, 1996); o fato de já ser considerada uma especialização médica; e, finalmente, o fato de estar experimentando uma revitalização de suas propostas e contar com centros atuantes, principalmente em São Paulo e Rio de Janeiro. Embora reconhecida como especialidade médica pelo Conselho Federal de Medicina, os entrevistados nesta pesquisa se aproximaram da homeopatia fora do ambiente universitário oficial.

Uma vez que o profissional da saúde conseguiu criar um caminho alternativo no serviço público ou na universidade, ele revela estar plenamente realizado, consciente da dificuldade da sua conquista em um mundo pouco tolerante com dissidências ao paradigma positivista. Como representante de um paradigma não hegemônico, a qualquer momento pode haver alguma forma de constrangimento, que vai desde uma crítica tolerante até um cerceamento às suas atividades, sob a alegação de estar exercendo uma atividade não-científica. Um projeto de pesquisa ou um pedido de participação em congresso internacional podem ser, por esse motivo, recusados, mesmo que sejam consistentes teoricamente.

No entanto, apesar de haver um certo perigo, principalmente em tempos em que os setores públicos, como a universidade, estão lutando por verbas cada vez mais escassas, há uma atmosfera de otimismo entre os profissionais que optaram por um caminho alternativo na prática ou na teoria médica. Todos consideraram que a crise na medicina mecanicista veio para ficar e que os paradigmas alternativos são respostas adequadas a essa crise. Os trechos de entrevista abaixo apontam esse aspecto:

"No começo, a terapia floral no serviço provocou um certo espanto entre os colegas. Escutei muita coisa desagradável, mas, com o tempo, as pessoas se acostumaram com a minha prática. A equipe de auxiliares de saúde e alguns colegas começaram a ver o trabalho dar resultado. Eles passaram a me encaminhar os piores casos $e$, principalmente os auxiliares de enfermagem, começaram a se tratar comigo" (Médica e professora da PUCCAMP).

"A Ciência, hoje, é extremamente materialista, pesada e sem encantos. A proposta que eu apresento é, muitas vezes, percebida como um bálsamo, um alívio romântico, que tem a sua beleza, mas que não é prática, não é viável. $\mathrm{Na}$ universidade, os professores, movidos por uma forte linha ideológica, são ainda mais radicais $e$ intolerantes. A influência do marxismo é muito grande, e a minha proposta é vista como ingênua, romântica ou mesmo ridícula. Eu não ligo, porque, sem confrontar ninguém, sem fazer muito barulho, eu contribuo para o crescimento do movimento holístico. Um dia, eu não tenho dúvidas de que ele será hegemônico" (Enfermeira e professora da UNICAMP).

\section{Considerações finais}

A partir da perspectiva aberta pelas representações sociais de profissionais das duas maiores universidades e da rede básica de serviços de saúde de Campinas, este artigo mostrou o significado simbólico relacionado ao termo "medicina alternativa", assim como o sentido forjado pela experiência de vida profissional desses atores sociais. Vimos que a postura de uma medicina alternativa não se coloca em oposição diante da postura tradicional repre- 
sentada pela medicina alopática, mas como uma dimensão que procura abarcá-la e, ao mesmo tempo, transcendê-la. Vimos também que, por detrás de grande diversidade de formas terapêuticas, provenientes de diversas tradições, há um sentido a unificá-las.

A ênfase no indivíduo (tomado como uma totalidade que compreende, além de seu corpo, sua interação social e familiar, suas crenças e valores, sua atitude diante da vida e da morte, sua noção de identidade, suas emoções, sua vida afetiva e sexual, seu trabalho e sua história pessoal) é fundamental na perspectiva alternativa. A doença, antes de ser percebida como um mero agente agressor externo que precisa ser combatido, é considerada como um distúrbio no equilíbrio desses vários elementos. A terapêutica lida com um nível energético vital que, supõe-se, antecede e determina, em última instância, as manifestações mecânicas no nível orgânico.

$\mathrm{O}$ artigo mostra, também, que o médico alternativo reconhece o problema que acomete o doente, através da sensibilidade, da intuição e do aspecto emocional relacionado com a empatia estabelecida no relacionamento médicopaciente. Sem excluir a razão e os princípios básicos da ciência, esses atributos são considerados fundamentais para o exercício profissional desse tipo de medicina. Nesse sentido, as práticas alternativas colocam-se numa posição radicalmente contrária à da medicina científica alopática, que adota, numa postura derivada do positivismo, uma divisão rígida entre sujeito e objeto, em que quanto maior a distância emocional do paciente, maior a objetividade.

Ao final desse artigo, após ter dimensionado o sentido da dissidência teórica e epistemológica de intelectuais diante do modelo científico hegemônico em ambiente universitário e da rede pública de serviços de saúde, cabe ainda uma palavra em favor da convivência democrática de diferentes paradigmas e abordagens científicas. É um pressuposto teórico fundamental deste trabalho a proposição de que um projeto teórico que dimensione uma realidade humana a partir de vários ângulos, projetando nela aspectos objetivos e subjetivos, sincrônicos e diacrônicos, estruturais e processuais, planos e profundos, produziria uma realidade mais rica do que a proposta unidimensional presente no paradigma científico hegemônico em nosso tempo.

Decorre desse pressuposto que, diante do contato com uma realidade estranha e incompatível com seus valores e medidas, ao invés de se desintegrar na relatividade, o pensamento científico teria exatamente, neste momento, a chance de se renovar e de crescer, escapando do enrijecimento dogmático e carência de vigor criativo. O verdadeiro papel da ciência humana nesse contexto seria, portanto, encontrar perspectivas mais universais que, embora assentadas num determinado paradigma, no interior de uma determinada cultura, teria como horizonte transcender qualquer sociedade, cultura ou momento histórico particular.

É nesse contexto que faz sentido desvendar sistemas de pensamentos deixados de lado pelo desenvolvimento da história e marginalizados pelo paradigma dominante de nosso tempo, principalmente aqueles que se preocupam com o sentido e o significado íntimo das coisas, com o númeno, que, desde Kant, foi considerado incognoscível e descartado pelo pensamento científico, por não poder ser medido e submetido às leis matemáticas. A característica fundamental dessa postura é trazer à tona, no momento mesmo da produção científica, dimensões que foram, desde Descartes, excluídas do campo de possibilidades de geração de conhecimento científico válido. Trata-se da sensibilidade, da intuição e da emoção que, quando harmonizados em sintonia com o intelecto, podem gerar estados mentais favoráveis ao dimensionamento de um mundo mais profundo e pleno de sentido.

Contudo, o interesse renovado no interior do pensamento científico moderno de questões relacionadas com significado, sentido e valor, apreendidas por faculdades humanas, tais como emoção, intuição e sensibilidade, expressa o fato de que o saber se processa dialeticamente e de que a experiência adquirida pela humanidade não precisa ser esquecida no desenvolvimento da história. Nesse contexto teórico, as propostas alternativas estudadas neste artigo mostram não apenas iniciativas individuais que se posicionam em sentido contrário à tendência dominante, mas iniciativas que, em um sentido mais amplo, exercem, em relação ao desenvolvimento da ciência, uma influência que a induz a um progresso qualitativo. 


\section{Agradecimentos}

Agradeço à Profa. Dra. Luisa Seravalle pela contribuição para a realização de algumas das entrevistas contidas no artigo e à FAPESP, CNPq e FAEP pelo apoio recebido para desenvolver este trabalho.

\section{Referências}

BOLTANSKY, L., 1979. As Classes Sociais e o Corpo. Rio de Janeiro: Editora Graal.

CAPRA, F., 1997. O Ponto de Mutação. São Paulo: Editora Cultrix.

COLLIER, R. J., 1988. Holography and integral photography. Physics Today, 6:87-98.

DURKHEIM, E., 1957. The Elementary Forms of the Religious Life. London: Allen \& Unwin.

FOX, R. C., 1975. Training for uncertainty. In: A Sociology of Medical Practice (C. Cox \& A. Mead, eds.), pp. 87-115, London: Collier-MacMillan.

HERZLICH, C., 1973. Health and Illness - A Social Psychological Analysis. London: Academic Press.

KUHN, T. S., 1975. A Estrutura das Revoluções Científicas. São Paulo: Editora Perspectiva.

KVALE, S., 1996. Interviews. An Introduction to Qualitative Research Interviewing. London: Sage Publication.

ILLICH, I., 1975. A Expropriação da Saúde. Rio de Janeiro: Nova Fronteira.

JOVCHELOVITCH, S. \& GUARESCHI, P., 1994. Introdução. In: Textos em Representações Sociais (S. Jovchelovitch \& P. Guareschi, orgs.), pp. 17-26, Petrópolis: Editora Vozes.

LÈVI-STRAUSS, C., 1970. Antropologia Estrutural. Rio de Janeiro: Tempo Brasileiro.

LUZ, M. T., 1988. Natural, Racional Social. Razão Médica e Racionalidade Científica Moderna. Rio de Janeiro: Editora Campus.

LUZ, M. T., 1996. A Arte de Curar versus a Ciência das Doenças. São Paulo: Dynamis.

MALINOWSKY, B., 1979. Argonautas do Pacífico Ocidental. São Paulo: Editora Abril.

MINAYO, M. C. S., 1992. O Desafio do Conhecimento. São Paulo: Editora Hucitec.

MOSCOVICI, S., 1976. La Psychanalyse, son Image et son Publique. Paris: Presses Universitaires de France.

MS (Ministério da Saúde), 1986. 8ạ Conferência Nacional de Saúde - Anais. Brasília: MS.

NAVARRO, V., 1976. Medicine under Capitalism. New York: Prodist.

O'NEAL, P., 1983. Health Crisis 2000. London: Alden Press.

QUEIROZ, M. S., 1982. The Social Construction of Health and Illness in Iguape, Brazil. Ph.D Thesis, Manchester: University of Manchester.
QUEIROZ, M. S., 1986. O paradigma mecanicista da medicina ocidental moderna: Uma perspectiva antropológica. Revista de Saúde Pública, São Paulo, 20:309-17.

QUEIROZ, M. S., 1991. Representações de Saúde e Doença. Campinas: Editora UNICAMP.

QUEIROZ, M. S., 1998. Um Enfoque Alternativo sobre Saúde e Doença: Uma Perspectiva Antropológica. Relatório Final de Pesquisa. Campinas: Convênio Universidade Estadual de Campinas/Departamento de Psicologia Médica e Psiquiatria/Fundação de Amparo à Pesquisa do Estado de São Paulo.

QUEIROZ, M. S. \& PUNTEL, M. A., 1997. A Endemia Hansênica: Uma Perspectiva Multidisciplinar. Rio de Janeiro: Editora Fiocruz.

SÁ, C. P., 1993. Representações sociais: O conceito e o estado atual da teoria. In: O Conhecimento no Cotidiano (M. J. Spink, org.), pp. 19-45, São Paulo: Editora Brasiliense.

SCHUTZ, A., 1973. Collected Papers I: The Problem of Social Reality. The Hague: Martinus Nijhoff.

SIMONTON, C., SIMONTON, S. \& CREIGHTON, J., 1978. Getting Well Again. Los Angeles: Tarcher.

SPINK, M. J., 1993. O estudo empírico das representações sociais. In: O Conhecimento no Cotidiano (M. J. Spink, org.), pp. 85-108, São Paulo: Editora Brasiliense.

SPINK, M. J., 1994. Desvendando as teorias implícitas: Uma metodologia de análise das representações sociais. In: Textos em Representações Sociais (S. Jovchelovitch \& P. Guareschi, org.), pp. 117148, Petrópolis: Editora Vozes.

TURNER, V. W., 1957. Schism and Continuity in an African Society: A Study of Ndembu Village Life. Manchester: Manchester University Press.

TURNER, V. W., 1966. Muchona the Hornet, interpreter of religion. In: In the Company of Man (J.B. Casagrande, ed.), pp. 97-116, New York: Harper. 